Technical Report

\title{
Improving Fluoroscopic Visualization for Lower Cervical Medial Branch Blocks with a Modified Swimmer's View: A Technical Report
}

David S. Stolzenberg, DO', Ryan Pfeifer, DO', Joshua Armstrong, DO', George Young, DO', Jeffrey Gehret, DO', Jeremy Simon, MD'1, and George C. Chang Chien, DO²

From: ${ }^{1}$ Department of Physical Medicine and Rehabilitation, Rothman Institute, Philadelphia, PA; ${ }^{2}$ Ventura County Medical Center, Ventura, CA

Address Correspondence: David Stolzenberg, DO Department of Physical Medicine and Rehabilitation Rothman Institute 925 Chestnut St., 5th Floor Philadelphia, PA 19107

Email: David.Stolzenberg@ rothmaninstitute.com

Disclaimer: There was no external funding in the preparation of this manuscript. Conflict of interest: Each author certifies that he or she, or a member of his or her immediate

family, has no commercial association (i.e., consultancies, stock ownership, equity interest, patent/licensing arrangements, etc.) that might pose a conflict of interest in connection with the submitted manuscript.

Manuscript received: 09-21-2017 Accepted for publication: 10-20-2017

Free full manuscript: www.painphysicianjournal.com
Background: Neural blockade of the cervical medial branches is a validated procedure in the diagnosis and treatment of cervical zygapophyseal joint pain. Fluoroscopic visualization of the lower cervical medial branch target zones (CMBTZs) in lateral view is sometimes challenging or not possible due to the patient's shoulders obscuring the target. Large shoulders and short necks often exacerbate the problem. Clear visualization is critical to accuracy and safety.

Objective: We aim to describe a method for optimal fluoroscopic visualization of the lower CMBTZs using a modified swimmer's view.

Study Design: A technical report.

Setting: A private practice.

Methods: Discussion with accompanying fluoroscopic images of the cervical spine, focusing on the lateral aspects of the lower cervical articular pillars in both the traditional lateral view and modified swimmer's view. Four authors served as volunteers for undergoing fluoroscopic x-rays in both views. Visualization of each lower CMBTZ was attempted and stored. The most caudal, clearly visualized levels were compared in both views for each participant.

Results: Visualization of the lower CMBTZs can be successfully obtained with the modified swimmer's view and in select patients is superior to a lateral view.

Limitations: A limitation to this study is the design as a technical report. A future prospective study is warranted.

Conclusions: Modified swimmer's view can serve as a primary method of visualizing the lower CMBTZs or an alternate view when a lateral view is unable to clearly demonstrate target landmarks. This can improve the ease, accuracy, and safety of performing diagnostic cervical medial branch blocks (CMBBs).

Key words: Swimmer's view, cervical medial branch block, facet joint, fluoroscopy

Pain Physician 2018; 21:303-308 eural blockade of the cervical medial branches is a validated procedure in the diagnosis and treatment of cervical zygapophyseal joint pain (1). Due to the depth and small size of these targeted structures, as well as approximation to sensitive neurovascular structures, an imaging modality is necessary to accurately and safely locate the targets for injection of medication (Fig. 1). Although some practitioners utilize ultrasound to localize these targets, these procedures are typically performed under fluoroscopic guidance. Fluoroscopically guided cervical medial branch blocks (CMBBs) are typically 
performed with anterior-posterior (AP) and lateral views (2). Limitations exist in the lateral view for obtaining cervical medial branch target zone (CMBTZ) visualization. Optimal visualization, particularly of the lower cervical levels, can be challenging if not impossible due to anatomical variations in patient morphology and limitations on body positioning for patient comfort. One common

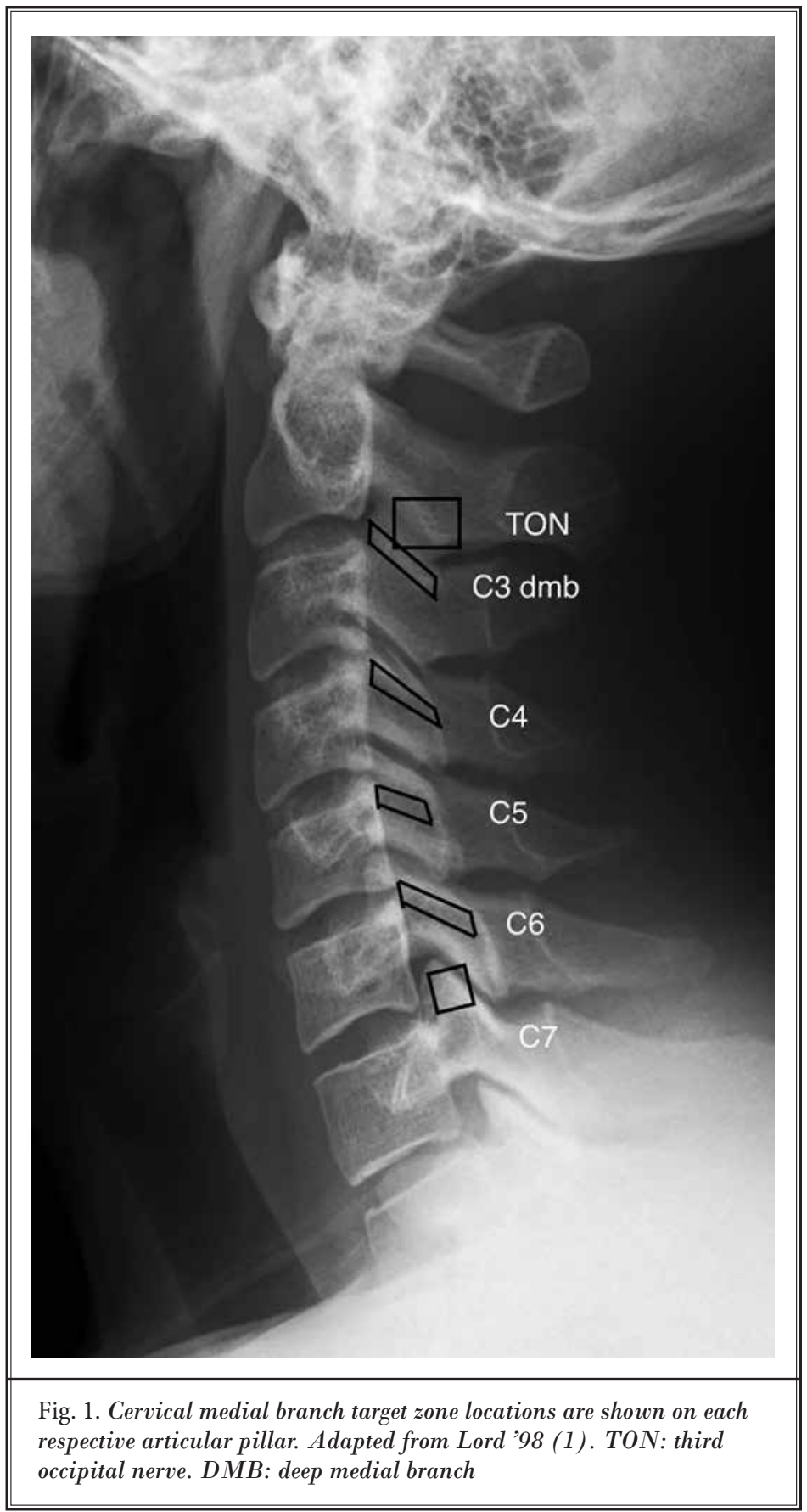

obstacle includes the patient's shoulders obscuring the fluoroscopic image. Despite repositioning by pulling both shoulders caudally, they can overlap the cervical segments within the $x$-ray beam's path. Large shoulders and shorter necks often exacerbate the problem (3).

The Spine Intervention Society Practice Guidelines state that "ideal images of the C7 level are more the exception than the rule (2)." The C5-6 and C6-7 facet joints are the first and third most common painful levels, respectively (4). Thus, optimal visualization of the lower CMBTZ is critical to confirm accurate needle and medication placement on the lateral cervical articular pillars on target zones as well as to safely avoid complications from violating nearby major neurovascular structures $(5,6)$.

We describe the use of a modification to the swimmer's view as a safe and effective alternative method for fluoroscopically guided visualization of the CMBTZ, which can minimize or negate the limitations on target visualization with standard AP and lateral views.

The swimmer's view is commonly utilized to improve visualization of pathology at the cervicothoracic junction, particularly after trauma (7-10). In a standard swimmer's view, one arm is abducted overhead, with the contralateral arm drawn caudally towards the patient's feet, thus removing the overlying shoulders from obscuring the lower cervical and upper thoracic spine during lateral x-rays (7-10). Swimmer's view has not been previously studied for the indication of visualizing CMBTZ and is not described in the major interventional pain atlases (1,3,11-13). One technical report describes its use for cervical intraarticular facet injections with posterior joint approach (14), which does not require clear visualization of the lateral aspects of the articular pillars where the cervical medial branches are located.

\section{Methods}

Four authors of this manuscript (DS, JA, GY, and RP) served as volunteers for undergoing fluoroscopic x-rays of the cervical spine. 


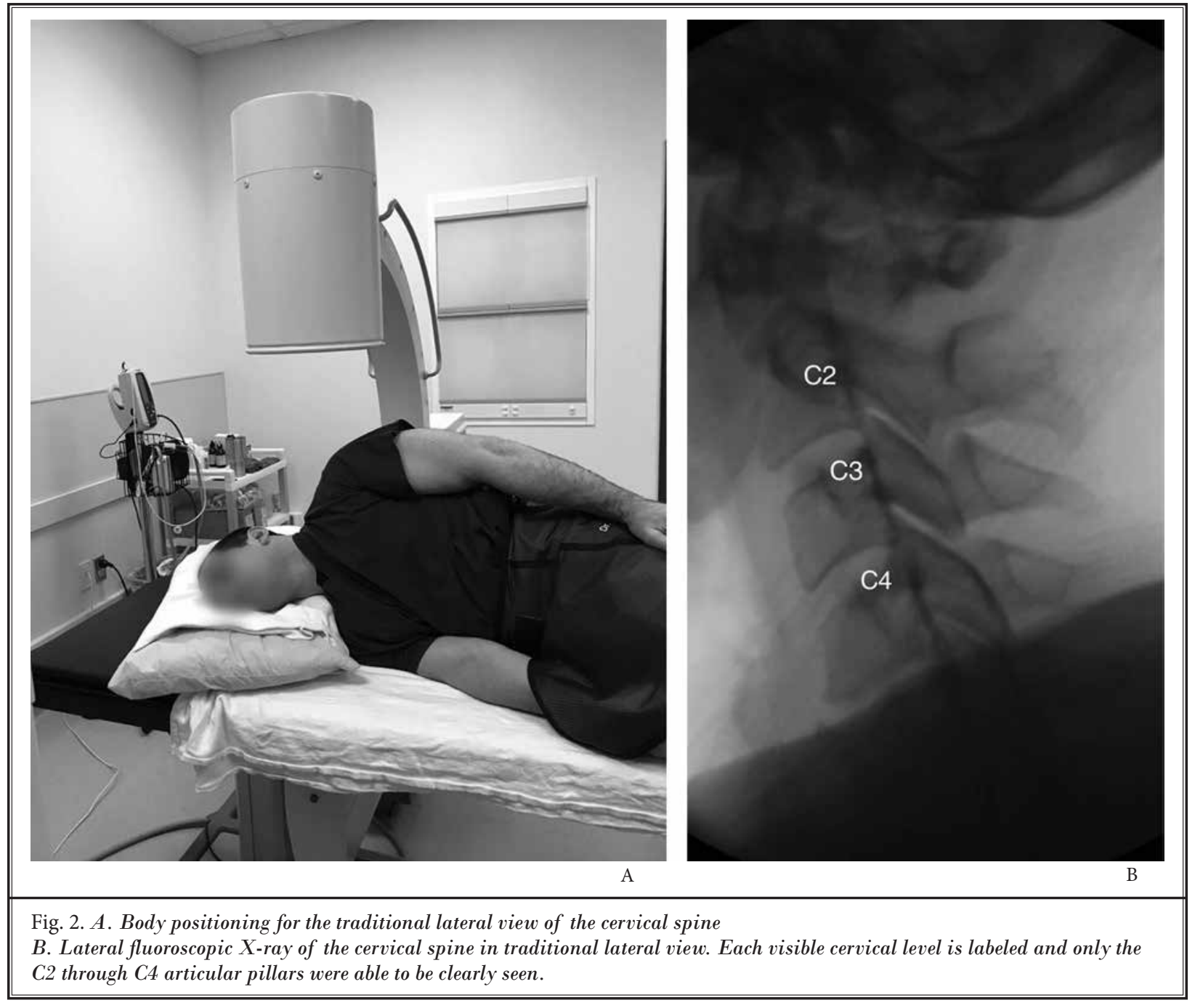

With the participant in lateral recumbent position, lateral views were initially obtained according to practice guidelines (2). Both shoulders were pulled caudally to optimize visualization of the CMBTZ and images were stored (Fig. 2A, 2B).

A modified swimmer's view was then obtained by elevating the contralateral (non-treatment side) shoulder cephalad toward the ear, then partially abducting the arm overhead and partially forward flexing the arm to be slightly in front of the head. The treatment side arm was then gently pulled caudad. A pillow was used for supporting the head in a neutral position, and the non-treatment side arm was above or below the pillow per preference for comfort (Fig. 3A, 3B). A true lateral $\mathrm{x}$-ray view was then obtained and images were stored (Fig. 4).
To perform a CMBB in clinical practice utilizing the modified swimmer's view, one uses the same standard technique that is typically used for a lateral approach of the procedure $(1,3)$. The only difference should be the improved visualization compared to the standard lateral view. Once the targeted levels are confirmed by counting down carefully from the $\mathrm{C} 2$ level, they are then centered on the fluoroscopic image to avoid parallax error before needle placement. We do not routinely get an AP image for depth, as it is confirmed by the tactile sensation of contact with bone. An example from the authors' practice is included for demonstration purposes (Fig. 5).

\section{Results}

Three of the 4 participants had non-visualization 

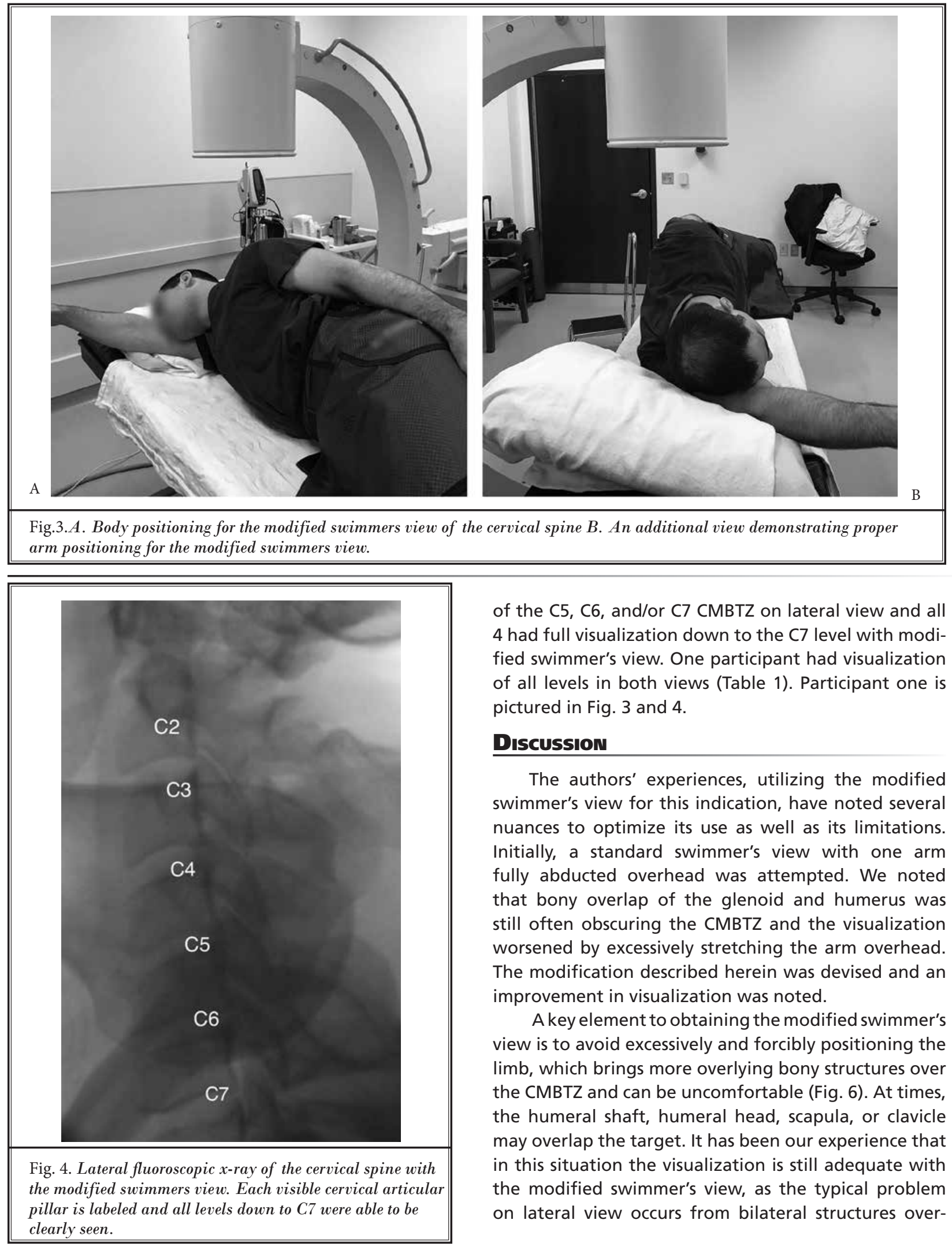

of the C5, C6, and/or C7 CMBTZ on lateral view and all 4 had full visualization down to the $\mathrm{C} 7$ level with modified swimmer's view. One participant had visualization of all levels in both views (Table 1). Participant one is pictured in Fig. 3 and 4.

\section{Discussion}

The authors' experiences, utilizing the modified swimmer's view for this indication, have noted several nuances to optimize its use as well as its limitations. Initially, a standard swimmer's view with one arm fully abducted overhead was attempted. We noted that bony overlap of the glenoid and humerus was still often obscuring the CMBTZ and the visualization worsened by excessively stretching the arm overhead. The modification described herein was devised and an improvement in visualization was noted.

A key element to obtaining the modified swimmer's view is to avoid excessively and forcibly positioning the limb, which brings more overlying bony structures over the CMBTZ and can be uncomfortable (Fig. 6). At times, the humeral shaft, humeral head, scapula, or clavicle may overlap the target. It has been our experience that in this situation the visualization is still adequate with the modified swimmer's view, as the typical problem on lateral view occurs from bilateral structures over- 


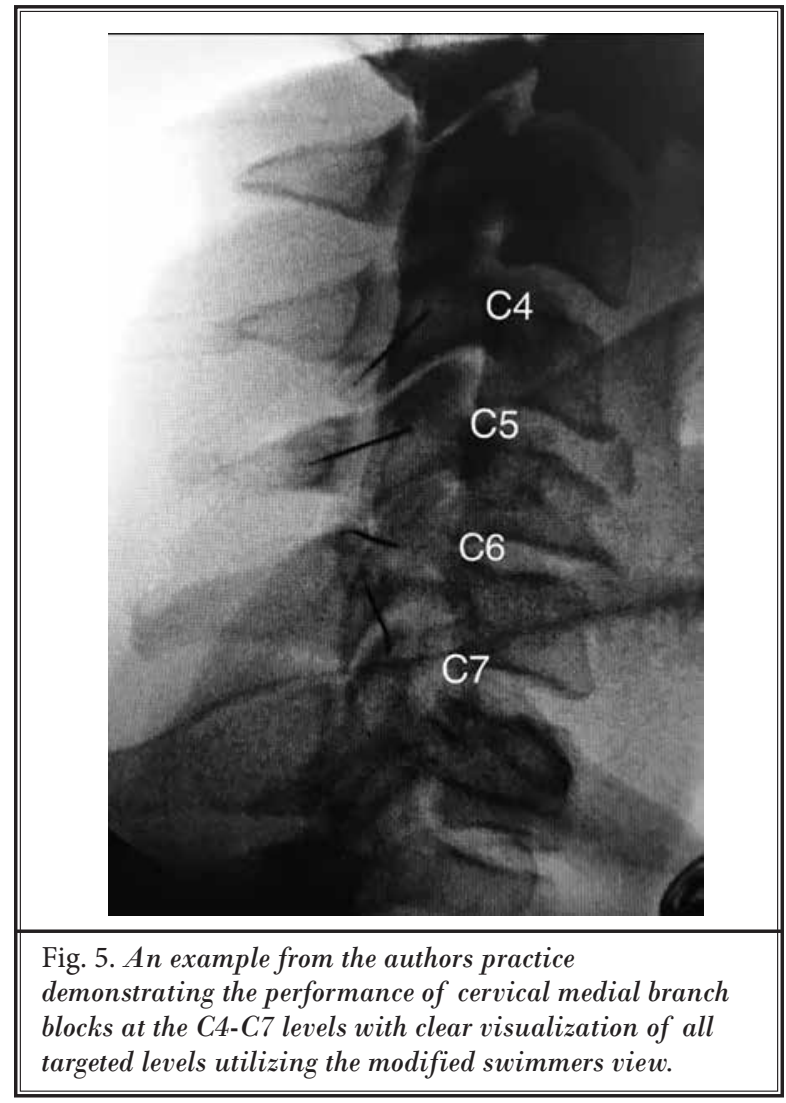

Table 1. Chart showing the most caudally visualized CMBTZ in each subject with the lateral view and modified swimmers view. CMBTZ: Cervical medial branch target zone.

\begin{tabular}{|c|c|c|}
\hline Subject & Lateral View & $\begin{array}{c}\text { Modified } \\
\text { Swimmers View }\end{array}$ \\
\hline 1 & C4 & C7 \\
\hline 2 & C5 & C7 \\
\hline 3 & C5 & C7 \\
\hline 4 & C7 & C7 \\
\hline
\end{tabular}

lapping the target. If visualization is impaired by the unilateral overlying structure, additional modifications of shoulder and arm position can be attempted, which typically involves less abduction and more forward flexion. Minimal patient repositioning, without moving the $\mathrm{C}$-arm, should bring the offending structure away from the CMBTZ; this can be observed in Fig. 4 and 6 as they are within the same participant.

Patients with shoulder pathology may have difficulty adequately positioning their arm for the modified swimmer's view. In this situation, we have noted

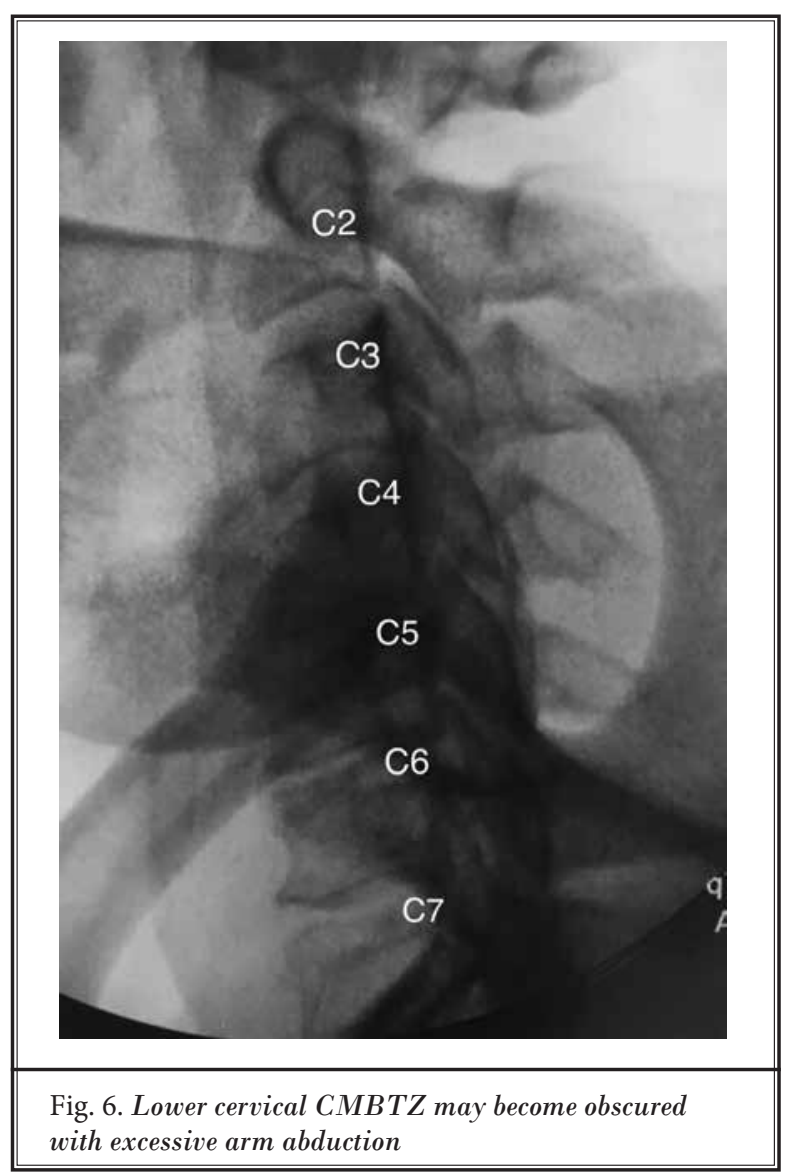

that simply raising the non-treatment-side shoulder cephalad a few inches, without abducting and flexing the arm, still allows for improved target visualization, as the ipsilateral shoulder and clavicle can more easily be depressed inferiorly.

A limitation to the modified swimmer's view is the performance of a bilateral procedure with lateral needle approach, as this requires re-positioning and reprepping the patient for the opposite side. Performing the procedure with a posterior needle approach would bypass this aspect. Additionally, the modifications to the standard swimmer's view may be more difficult to achieve with the patient in a prone or supine position as compared to the side-lying position. This is due to the need for arm support with the limb partially abducted and flexed.

The modified swimmer's view may also be used for cervical intraarticular facet injections with a lateral approach. Procedures that require a prone posterior approach, such as cervical radiofrequency ablation and cervical interlaminar epidural steroid injections, will 
not likely be able to be optimally performed with this view due to the difficulty obtaining the proper arm modifications to the swimmer's position from a prone position, as discussed in the previous paragraph. The modified swimmer's view for CMBBs has the potential to become commonly utilized in clinical practice in a similar fashion to the contralateral oblique view for cervical interlaminar epidural steroid injections.

\section{Conclusion}

The modified swimmer's view can be used as a primary view for lower CMBB or an optional view when lateral view does not provide adequate CMBTZ visualization. This can improve the ease and accuracy of performing lower CMBBs. It may also minimize patient risk of injury to nearby neurovascular structures and potentially reduce unnecessary radiation exposure for the patient and medical staff.

Future prospective studies comparing visualization between both views would be needed to determine if the modified swimmer's view provides superior visualization, safety, patient comfort, and reduced radiation and procedural time over traditional lateral view of the CMBTZs.

\section{Acknowledgments}

The authors wish to thank Kaitlin Prutzman, radiologic technologist, for her assistance with obtaining the fluoroscopic images for this manuscript.

\section{References}

1. Lord SM, McDonald GJ, Bogduk N. Percutaneous radiofrequency neurotomy of the cervical medial branches: A validated treatment for cervical zygapophysial joint pain. Neurosurg Quarterly 1998; 8:288-308.

2. Bogduk N. Cervical medial branch blocks. In: Bogduk N (ed). Practice Guidelines for Spinal Diagnostic and Treatment Procedures. 2nd ed. Spine Intervention Society, San Francisco 2013, pp 101-140.

3. Conly JR, Parikh TN, Furman MB. Cervical zygapophysial joint nerve (medial) injection, lateral approach. In: Furman MB (ed). Atlas of Image-Guided Spinal Procedures. Elsevier Saunders, Philadelphia 2013, pp 279-288.

4. Cooper G, Bailey B, Bogduk N. Cervical zygapophysial joint pain maps. Pain Med 2007; 8:344-353.

5. Fitzgibbon DR, Posner KL, Domino KB, Caplan RA, Lee LA, Cheney FW; American Society of Anesthiologists. Chronic pain management: American Society of Anesthesiologists Closed Claims Project. Anesthesiology 2004; 100:98-105.

6. Goldstone JC, Pennant JH. Spinal anaesthesia following facet joint injection. Anaesthesia 1987; 42:754-756.

7. Rethnam U, Yesupalan RS, Bastawrous SS. The swimmer's view: Does it really show what it is supposed to show? A retrospective study. BMC Med Imaging 2008; 8:2.

8. Toksoy A, Bektas F, Eken C, Ceken K, Cete $Y$. Value of the swimming position and arm traction in visualizing the cervicothoracic junction over the standard lateral cervical x-ray. Int J Emerg Med 2010; 3:85-90.

9. Daffner SD, Vaccaro AR. Managing disorders of the cervicothoracic junction. Am J Orthop (Belle Mead NJ) 2002; 31:323-327.

10. Gisbert VL, Hollerman JJ, Ney AL, Rockswold GL, Ruiz E, Jacobs DM, Bubrick MP. Incidence and diagnosis of $\mathrm{C}_{7}-\mathrm{T}_{1}$ fractures and subluxations in multiple- trauma patients: Evaluation of the advanced trauma life support guidelines. Surgery 1989; 106:702-708.

11. Rathmall JP. Facet injection: intra-articular injection, medial branch block, radiofrequency treatment. In: Rathmell JP (ed). Atlas of Image-Guided Interventions. 2nd ed. Lippincott Williams and Wilkins, Philadelphia 2012, pp 80-117.

12. Fenton DS, Czervionke LC. Facet joint injection and medial branch block. In: Fenton DS, Czervionke LC (eds). ImageGuided Spine Intervention. Saunders, Philadelphia 2003, pp 9-50.

13. Waldman SD. Cervical facet block: medial branch technique. In: Waldman SD (ed). Atlas of Interventional Pain Management. 4th ed. Saunders, Philadelphia 2014, pp 161-168.

14. Kulkarni AG, Sabet T, Ashley H, Diwan AD. Technical note: The swimmer's view for cervical facet joint injections. Eur Spine ] 2006; 15:1150-1152. 